\title{
LOS FOGONES EN LA MESETA CENTRAL DE SANTA CRUZ DURANTE EL PLEISTOCENO FINAL
}

ARIEL D. FRANK"

\section{RESUMEN}

En este artículo desarrollamos investigaciones acerca de las estructuras de combustión utilizadas, durante el Pleistoceno final, en la meseta central de Santa Cruz, Argentina. Los estudios se realizan sobre los fogones identificados en la unidad 5 del sitio Cerro Tres Tetas 1 y en las unidades 4 y 3 inferior del sitio Casa del Minero 1. Estudiamos algunas de sus características - morfología, tamaño, cercanía a las paredes de la cueva y a la línea de goteo, distancia entre sí - y evaluamos la forma en que ciertos factores afectaron su conformación. Asimismo, comparamos de manera preliminar la información presentada con aquella disponible para la región de Magallanes, Chile, en momentos similares.

Las características de los fogones -planos y sin estructuras limitantes-son acordes con ocupaciones poco intensas, donde se encienden fuegos que requieren poca inversión de energía en su acondicionamiento. Asimismo, las evidencias indican que la fluctuación en los tamaños de los fogones podría estar vinculada a cambios en la intensidad de ocupación. La abundancia de hogares, muchas veces ubicados de manera cercana entre ellos o inclusive superpuestos podrían estar evidenciando una sucesión de ocupaciones en las cuevas, así como una redundancia en la elección de los espacios utilizados para encender fogones. Finalmente, las comparaciones de los fogones analizados con las estructuras "Fell 1" indican que posiblemente se hayan desarrollado dos estrategias distintas con respecto al diseño de los fogones en estos dos espacios de la Patagonia meridional

PALABRAS CLAVE: fogones, meseta central, pleistoceno final, manejo del fuego. 


\title{
HEARTHS IN THE CENTRAL PLATEAU OF SANTA CRUZ DURING THE FINAL PLEISTOCENE
}

\begin{abstract}
In this paper we investigate the combustion structures used during the final Pleistocene in the central plateau of Santa Cruz, Argentina. We analyze the hearths from unit 5 of site Cerro Tres Tetas 1 and from units 4 and 3 inferior of site Casa del Minero 1. We study some of their characteristics -morphology, size, proximity to cave walls and to the drip line, distance between each other- and evaluate the way in which certain factors affected their conformation. Additionally, we perform an initial comparison with hearths with similar chronologies from the region of Magallanes in Chile.

The analyzed hearths are flat and lack any limiting structure; therefore they are in accordance with low-intense occupations in which fire ignition involves little energy. Evidence indicates that the fluctuation in the size of hearths might be related to changes in occupation intensity. The abundance of hearths, which are in many cases located near each other or even overlapped shows a series of occupations in caves as well as redundancy in the selection of the place in which to light the hearths. Finally, comparisons with "Fell 1" hearths suggest two different strategies regarding hearth design in these two areas of southern Patagonia.
\end{abstract}

KEY WORDS: hearths, central plateau, final pleistocene, fire management.

\section{INTRODUCCIÓN}

El fuego es y ha sido una herramienta fundamental en la vida de las sociedades cazadoras recolectoras. Constituye una de las primeras adopciones humanas, ha tenido un fuerte valor adaptativo puesto que brinda calefacción e iluminación y permite la cocción de alimentos. Ha posibilitado la colonización de ambientes hostiles y constituido una forma de protección ante depredadores. Asimismo, ha sido utilizado como herramienta en el procesamiento de recursos.

El manejo del fuego, entendido como el conjunto de actividades relacionadas con la apropiación de los insumos, el encendido, el mantenimiento, el uso y el apagado del fuego (Frank 2011b; Pérez de Micou 1991; Théry-Parisot et al. 2010), ha sido poco explorado en la arqueología patagónica a pesar de que es común hallar estructuras de combustión y restos arqueológicos termoalterados en los sitios de esta región. Si bien es cierto que los estudios antracológicos de carbones se encuentran en desarrollo y están arrojando valiosa información (por ejemplo Piqué 1999), otras características fundamentales como las dimensiones, la morfología o la distribución en planta de los fogones suelen faltar. Salvo excepciones (ver por ejemplo Bird 1988; Massone et al. 1998;
Massone 2002, 2004; Paunero et al. 2007), las referencias a éstos en los sitios arqueológicos de la región se limitan a estipular su presencia o ausencia y en algunos casos a destacar que los restos se hallaron en las cercanías a estas estructuras.

En este contexto, consideramos que es importante presentar información relativa a estas cuestiones, puesto que nos permiten indagar diversos aspectos vinculados a las estrategias de uso del espacio intrasitio, a la intensidad de ocupación y a las actividades realizadas utilizando el fuego o alrededor de los fogones. Así, en este trabajo pretendemos aportar al conocimiento de las estructuras de combustión utilizadas, durante el Pleistoceno final, en la meseta central de Santa Cruz. De manera más especíica, deseamos estudiar determinadas características de estas estructuras -ubicación, morfología, tamaño- y evaluar la manera en que ciertos factores afectaron su conformación. Asimismo, buscamos comparar la información presentada con aquella disponible para otras regiones conexas, en momentos similares. Los estudios se realizan sobre los fogones identificados en la unidad 5 del sitio Cerro Tres Tetas 1 y en las unidades 4 y 3 inferior de Casa del Minero 1; los tres componentes presentan fechados que los enmarcan temporalmente en el Pleistoceno final (Paunero 2009a; Paunero et al. 2007). 


\section{ASPECTOS RELATIVOS A LAS ESTRUCTURAS DE COMBUSTIÓN}

Las estructuras de combustión son rasgos arqueológicos factibles de ser reconocidos por la concentración de restos de combustión (ceniza y carbones, entre otros) en un área restringida, asociados a superficies quemadas o rubificadas (Marconetto 2005). Aunque Pérez de Micou (1991) distingue para la Patagonia entre "fuegos, fogones y señales", consideramos que la diversidad en funcionalidad existente es mayor a la que puede ser expresada por estos tres conceptos. Así, diferenciamos únicamente dos tipos de estructuras, que se vinculan al modo en que se obtiene el combustible que será utilizado para su encendido y que pueden tener diversas utilidades. Por un lado los fogones, por lo general domésticos, habitualmente encendidos en el campamento para los que es necesario recolectar leña y acondicionar el espacio. Por el otro, los "fuegos", para los que se aprovechan las matas y arbustos en pie (Frank 2011a).

Los fogones domésticos, de acuerdo a su morfología y relación con la superficie de ocupación (Leroi-Gourhan 1979; Marconetto 2005; Vallverdú et al. 2011), se pueden clasificar en:

- Planos o en plato: la combustión se da sobre una superficie plana, alcanzando temperaturas bajas y regulares.

- En cubeta: la combustión se produce dentro de un área excavada artificialmente o de origen natural. Se asocia a combustiones más largas.

- Sobre-elevados: La combustión se produce en un área elevada con respecto al nivel del piso.

Las mencionadas estructuras pueden tener sus límites definidos de diversos modos, como por ejemplo, un cerco de piedras. Mientras que los fogones sin arreglos limitantes pueden transferir calor mediante radiación, aquellos que tienen paredes conformadas por piedras, o cuentan con piedras en su interior, también pueden hacerlo mediante convección, por lo que constituyen formas óptimas para ambientes muy fríos (Odgaard 2003).

Se ha propuesto que las características de las estructuras de combustión pueden variar de acuerdo a diversos factores. Entre ellos, se considera que tendrán diferente morfología según la intensidad de ocupación - definida por la interacción entre el tamaño del grupo y la duración de la ocupación
(Nakazawa 2007)-. Los fogones en cubeta permiten alcanzar mayores temperaturas y la combustión tiende a ser prolongada, mientras que en los fogones planos la temperatura suele ser más regular pero también más baja y en estos el fuego tiene menor duración (Leroi-Gourhan 1979; Marconetto 2005; Nakazawa 2007). De esta manera, teniendo en cuenta que por lo general es necesario realizar una mayor inversión de energía para la formatización de las estructuras en cubeta, se espera que las mismas se asocien a ocupaciones más intensas, mientras que los fogones planos serían preponderantes en ocupaciones de menor intensidad (Nakazawa 2007; Pérez de Micou 1991).

Por otro lado, se ha postulado que también el tamaño de los hogares depende de la intensidad de la ocupación (Chatters 1987). De acuerdo a Chatters, cuanto más larga sea una ocupación, más grandes serán éstos y más difusos sus límites. Una observación similar realizan Bartram y colaboradores (1991), quienes notan que entre los Kua los fogones utilizados de manera más intensa en un asentamiento -aquellos usados durante todo el díacrecen en tamaño más rápidamente que aquellos empleados durante solo cierta parte del día o para actividades especiales. Asimismo, Pérez de Micou (1991), en base a estudios etnoarqueológicos considera que las estructuras en forma de cubeta no son esperables dentro de cuevas y aleros, y que en caso de reconocerse, estas no serían producto de un cavado intencional sino como consecuencia de la limpieza y reactivación del fogón. En contraste, de acuerdo a los estudios de Galanidou (2000) acerca del uso de hogares dentro de cuevas, no existiría una correlación entre la duración de la ocupación y la energía invertida en el acondicionamiento de esta estructura. Por el contrario, observa que el tipo de estructura sería dependiente del grado de movilidad del grupo.

Alternativamente, Pérez de Micou (1991) considera que existiría, en el caso de la Patagonia, una relación directa entre el tamaño del fogón y la cantidad de gente involucrada en su uso. De acuerdo a esta autora: los fogones grandes, cavados, sugieren un uso común en la cocción de alimentos principales mientras que los "fuegos" pequeños sugieren calentamiento individual o de pequeños grupos [...] Esta relación se comprueba sólo cuando en un mismo contexto se asocian 
ambos tipos de estructuras de combustión (Pérez de Micou 1991: 138).

Una cuestión a tener en cuenta en vinculación al tamaño es que no siempre un grupo reutilizará las estructuras de combustión preexistentes en un asentamiento. Por el contrario, en algunos casos se prefiere encender otro fuego generándose, en consecuencia, una multiplicidad de hogares, que pueden o no estar funcionando en el mismo momento (Galanidou 2000). Esto lleva a considerar la importancia de la distribución de los fogones dentro de un sitio. Son valiosos los aportes de Henry (2003, 2010), quien basándose en una muestra arqueológica y etnográfica de fogones encendidos dentro de cuevas y aleros, ha planteado una serie de consideraciones que resultan interesantes de tratar aquí. Por un lado, afirma que la posición de los fogones tiende a estar más vinculada a la pared de las cuevas que a la línea de goteo. Mientras que en su recopilación la distancia media de los hogares a la línea de goteo es de 2,2 metros, la que separa a dichas estructuras de la pared más cercana de una cueva es de 1,3 metros. Esto es, los fogones suelen ubicarse cercanos a las paredes, y más alejados de la entrada a la cueva. Según el autor, menos del 2\% de los hogares registrados en sitios reparados se ubicaban por fuera de la línea de goteo (Henry 2003).

Otro rasgo al que hace referencia es la separación entre fogones de una misma superficie de ocupación. De acuerdo a sus registros, la distancia promedio, tomando como referencia el punto central de las estructuras, sería de aproximadamente 2,4 metros y disminuiría hasta 1,4 metros en aquellos pisos de ocupación que cuentan con 11 fogones. Estos valores podrían vincularse tanto a la superposición de diversas ocupaciones como al empleo de varios fogones de manera simultánea, lo que se relacionaría con la fluctuación en la cantidad de personas habitando una cueva en un momento dado (Henry 2003, 2010).

Asimismo, Henry (2010) afirma que en contextos arqueológicos de cuevas y aleros, la densidad promedio es de un fogón cada $14,7 \mathrm{~m}^{2}$ mientras que en los contextos etnográficos la media es de uno cada 23,6 $\mathrm{m}^{2}$. El número de fogones promedio para sitios arqueológicos es de 4,7 contra 4,2 en contextos etnográficos; sin embargo la cantidad máxima registrada para los primeros es de 11 mientras que para los últimos es de 6. Esto indicaría que un piso de ocupación que muestra más de seis estructuras sería producto de más de un episodio ocupacional.

Por otra parte, los diversos usos para los que se aprovecha el fuego implican también diferencias en sus características. De este modo, la forma en que se maneje y gestione un fuego en una determinada sociedad dependerá entre otras cosas de la función a la que será destinado. Cada actividad lleva implícita el conocimiento de los combustibles apropiados para ella; además sus diversos usos se relacionan con las necesidades de producción y reproducción de cada sociedad (Marconetto 2005, 2006; Théry-Parisot et al. 2010).

Es probable, sin embargo, que un mismo fogón pueda ser utilizado en variadas actividades (Galanidou 2000). De acuerdo a Galanidou, tanto los fogones planos, sin estructuras que limiten su tamaño, como aquellos rodeados por piedras o troncos pueden ser utilizados para múltiples propósitos. En esta misma línea de argumentación, Manzi y Spikins (2008) afirman que [Las] formas que asumieron las estructuras de combustión, tipificadas como fogones planos y en cubeta, no son por sí solas representativas de la alta variedad de funciones $y$ de las actividades en las que pudieron haber sido utilizadas, ni de los múltiples usos en los que pudieron haber intervenido. Puede esperarse que una misma forma de estructura de combustión hubiera sido utilizada tanto con fines simbólicos [...], como para calentar, cocinar alimentos, preparar pigmentos y manufacturar astiles para puntas de proyectiles, entre otras posibilidades (Manzi y Spikins 2008: 92). Esto es posible siempre que sus características cubran los requerimientos mínimos para cada una de ellas.

Por otra parte, en sociedades cazadoras recolectoras muchas de las actividades llevadas a cabo en un sitio se desarrollan en torno a las estructuras de combustión, vinculándose así los fogones al diseño y organización del espacio. A partir de estudios etnoarqueológicos y de distribución espacial intrasitio, se ha planteado que es esperable encontrar una parte importante de los restos arqueológicos alrededor de las estructuras de combustión -lo que se conoce como Hearth-associated artifact assemblages en la literatura en inglés (Alperson-Afil 2008; Bamforth et al. 2005; Binford 1994; Nakazawa 
2007; O'Connell 1987; Stevenson 1991; Vaquero y Pastó 2001, entre otros). Esta agrupación en torno a los fogones constituiría una estrategia de manejo del espacio característica de los grupos cazadores recolectores (Vaquero y Pastó 2001).

$\mathrm{Al}$ ser un punto que articula diversas actividades, el fogón es un espacio socializador, donde ocurren interacciones que posibilitan la reproducción de las relaciones sociales. Muchas de las actividades que se desarrollan en torno a él no requieren de su presencia. Así, la concentración de actividades a su alrededor puede explicarse por el valor social de este espacio (Vaquero et al. 2004).

\section{LOS SITIOS EN ESTUDIO}

Los sitios Casa del Minero 1 (CDM1) y Cerro Tres Tetas 1 (C3T1) -ubicados en las localidades arqueológicas La María y Cerro Tres Tetas respectivamente- han sido estudiados intensamente desde diversas perspectivas (Cueto et al. 2010; Frank 2009b, 2011b; Frank y Paunero 2009; Frank et al. 2007; Paunero 2000a, b, 2009a, b; Paunero y Castro 2001; Paunero et al. 2007; Paunero et al. 2008; Skarbun 2009; Skarbun et al. 2007; Skarbun y Frank 2011). Se trata de dos cuevas que han arrojado una sucesión de ocupaciones, desde el Pleistoceno final hasta principios del siglo XX.

En el caso de C3T1, la cueva está orientada hacia el oeste, a $110 \mathrm{~m}$ de distancia de una vertiente actual y a una altura sobre ésta de 9,13 m. Es una cueva oscura, cubierta en su techo por hollín y con manifestaciones rupestres en sus paredes, entre ellas una escena de caza mediante lazo cuya antigüedad correspondería al Pleistoceno final (Podestá et al. 2005). La profundidad máxima de la cueva es de 11 $m$ entre la línea de reparo y el fondo. Su altura es de 1,50 m en el interior y de 2,60 m en la parte más externa. El ancho de la cueva propiamente dicha no excede los $11 \mathrm{~m}$, pero en la parte externa supera esa dimensión pues se continúa con un alero totalizando en este caso $21 \mathrm{~m}$ de entrada. Su excavación fue realizada durante los años 1994 y 1995; se abrieron 9 cuadrículas con una superficie total de $12,25 \mathrm{~m}^{2}$ (Paunero 2000a), es decir alrededor del 7,2\% de la superficie total reparada que, contabilizando el alero, es de aproximadamente $170 \mathrm{~m}^{2}$.

Las unidades estratigráficas en el sitio presentan límites bien marcados, buena con- servación de los elementos arqueológicos y una relativa horizontalidad. La unidad 5 corresponde al Pleistoceno final, habiendo arrojado fechados que van desde los 11.560 años ${ }^{14} \mathrm{C}$ AP hasta los 10.260 años ${ }^{14} \mathrm{C}$ AP (Paunero y Castro 2001). Esta unidad ha brindado abundantes restos líticos y escasos desechos óseos.

El conjunto lítico se caracteriza por presentar una alta predominancia de materias primas silíceas, de origen local, de muy buena calidad para la talla. Son preponderantes los restos correspondientes a las etapas finales de formatización de los instrumentos; estos son en su gran mayoría unifaciales (Paunero 2009a; Paunero y Castro 2001). Entre los procedimientos de formatización de artefactos identificados se encuentra el tratamiento térmico, aplicado fundamentalmente sobre formas base, previo a la formatización final de los artefactos (Frank 2011b).

De acuerdo al análisis funcional de base microscópica de los artefactos líticos, se identificaron dos actividades principales, una de raspado y otra de corte, ambas principalmente sobre cuero y en menor medida sobre hueso. La distribución de los artefactos en el sitio llevó a afirmar que estas tareas se desarrollarían en sectores diferentes de la cueva, conformando áreas de actividad, principalmente alrededor de los fogones (Paunero y Castro 2001).

Se recuperaron escasos restos óseos, que muestran un buen estado de conservación. Son en su mayoría fragmentos indeterminados. De los muy pocos casos en que pudo determinarse un taxón, éste correspondió a Lama guanicoe (Paunero 2009a). Esto llevó a Paunero a considerar que la fractura intencional de huesos largos y el consumo de médula ósea fueron realizados en el sitio solo circunstancialmente. Se reconocieron dos instrumentos confeccionados sobre hueso: un punzón y una diáfisis de tibia de guanaco con retoques marginales en uno de sus bordes. De acuerdo al análisis contextual, así como a las características de los artefactos, se ha postulado que éstos fueron utilizados para tareas de procesamiento secundario en cuero (Paunero et al. 2008).

Con respecto a CDM1, la cueva se encuentra orientada hacia el oeste, a 29 m de un zanjón, a una altura de 5,83 m sobre el cauce del mismo. Sus entradas naturales actualmente están cerradas por un empircado realizado por mineros que ocuparon 
el lugar entre los años 1920 y 1960 (Paunero et al. 2007). El largo máximo de la cueva es de 11,76 $\mathrm{m}$, medido de $\mathrm{N}$ a S, el ancho máximo de $\mathrm{E}$ a $\mathrm{O}$ es de 5,80 m; abarca una superficie de $68,20 \mathrm{~m}^{2}$. La altura medida desde el piso actual al techo oscila entre 1,20 a 2,20 m. Entre los años 2000 y 2004 se excavaron $15,32 \mathrm{~m}^{2}$, lo que representa el 22,5\% de la superficie total.

Al igual que en C3T1, los niveles estratigráficos presentan horizontalidad y buena conservación de los elementos. En este caso, son dos las unidades que presentan restos asignables al Pleistoceno final. La unidad 4 fue fechada en ca. 11.000 años ${ }^{14} \mathrm{C}$ $\mathrm{AP}$, mientras que la unidad 3 inferior cuenta con un fechado de 10.250 años ${ }^{14} \mathrm{C}$ AP. Ambas se encuentran separadas entre sí por una clara línea de rocas de derrumbe (Paunero et al. 2007).

Las características de ambas unidades remiten a ocupaciones tempranas en el poblamiento de la región. El conjunto lítico se caracteriza por la amplia predominancia de restos producidos en sílex rojo, materia prima de muy buena calidad para la talla, cuya fuente se ubica a menos de un kilómetro de distancia del sitio. Si bien cada una cuenta con sus particularidades, podemos decir que en ambas unidades es preponderante la presencia de productos de talla, habiendo muy baja cantidad de instrumentos y total ausencia de núcleos. Las actividades de producción están orientadas en la unidad 4 principalmente a la formatización final de artefactos mientras que en la unidad 3 inferior es importante también la producción de soportes. En las dos unidades las actividades de talla lítica tienden a realizarse en torno a las estructuras de combustión. En ambos componentes los instrumentos son unifaciales, aunque en la unidad 4 hay dos artefactos que presentan un leve retoque bifacial. Asimismo, en esta unidad es notoria la presencia de lascas de adelgazamiento bifacial y la aplicación del tratamiento térmico. Los estudios funcionales de microdesgaste en los instrumentos han indicado tareas de raspado de cuero y corte de hueso en la unidad 4, mientras que en la 3 inferior dichos análisis se encuentran en desarrollo en la actualidad (Cueto et al. 2010; Frank 2009b, 2011b; Frank et al. 2007; Skarbun 2009; Skarbun et al. 2007; Skarbun y Frank 2011).

En relación con el conjunto óseo, el registro zooarqueológico de la unidad 4 incluye tres especies de camélidos: el guanaco y dos extintos (Hemiauchenia paradoxa y Lama gracilis), dos variedades de cánidos (Lycalopex griseus y elementos que corresponden a Lycalopex culpaeus o bien a Dusicyon avus) y Rhea sp.. Los restos óseos tienden a agruparse alrededor de los fogones; su estado de conservación es bueno. El análisis de los conjuntos ha permitido inferir actividades de procesamiento primario y consumo, según las evidencias de fracturas helicoidales, longitudinales, lascados, termoalteraciones y marcas de corte (Frank 2011b; Paunero et al. 2007; Paunero et al. 2008). Se registró la presencia de 2 punzones y un retocador extremo lateral elaborados sobre diáfisis de camélido. Estos habrían sido confeccionados en el lugar de acuerdo con los remontajes de elementos realizados en el laboratorio (Paunero et al. 2004; Paunero et al. 2008).

En contraste, el conjunto faunístico de la unidad 3 inferior es pequeño, presenta una disminución en el número de taxones en comparación con la unidad 4; identificamos principalmente Lama guanicoe. Observamos escasas evidencias de acción humana, es importante mencionar la presencia de un artefacto elaborado sobre diáfisis de Lama sp.. Se trata de una porción con punta roma en un extremo que presenta desgaste por probable presión sobre piedra u otro elemento duro. En general los elementos del componente presentan un buen estado de conservación al igual que en el componente anterior (Paunero et al. 2007; Paunero et al. 2008).

De esta manera, los componentes pleistocénicos de ambos sitios presentan características que remiten a la colonización inicial del territorio patagónico. Dicha fase, ocurrida en un marco de fluctuaciones ambientales, habría sido un proceso lento, caracterizado por una demografía muy baja (Borrero 1989-90, 1994-1995; Miotti y Salemme 2004; Paunero 2009b), con ritmos no constantes, avances y retrocesos de las poblaciones y ocupaciones de corta duración (Borrero 1999; Paunero 2009b). En este contexto, el fuego debe haber jugado un papel importante en el poblamiento de los nuevos espacios, puesto que tiene un fuerte valor adaptativo en la colonización de ambientes fríos (Manzi y Spikins 2008; Odgaard 2003). Como la estadía en los sitios debió haber sido breve, y los grupos de pequeño tamaño, los fogones debieron haber tenido corta duración y haber sido encendidos para pocos individuos (Stadler 2002; Stadler et al. 2003). 


\section{LOS FOGONES ENCENDIDOS EN LA MESETA CENTRAL DURANTE EL PLEISTOCENO FINAL}

\section{Aspectos Metodológicos}

Analizamos las estructuras de combustión presentes en los componentes pleistocénicos de CDM1 y C3T1. Al ser cuevas en las cuales no hay evidencias de desarrollo de suelos, podemos definir a todas las estructuras de combustión reconocidas en ellos como fogones. Relevamos sus características, teniendo en cuenta su morfología, su relación con la superficie de ocupación y su formatización (Leroi-Gourhan 1979; Marconetto 2006). Asimismo, registramos sus dimensiones en planta, considerando su longitud máxima y el ancho medido perpendicularmente al largo en el centro de la estructura.

También consideramos su distribución espacial dentro del sitio, evaluando la distancia de cada uno a la línea de goteo y a las paredes de la cueva, así como la distancia horizontal entre ellos. En este sentido cabe aclarar que hemos tomado las medidas tanto desde el centro de los fogones como desde sus límites. Si bien algunos autores realizan las mediciones únicamente desde el punto central del fogón (Henry 2010), pensamos que resulta adecuado registrar ambas, ya que la distancia tomada desde los límites nos brinda una mejor idea del espacio disponible para ser ocupado por las personas que habitaron la cueva.

La información proviene de los datos registrados en las libretas de campo, los mapas de distribución de fogones confeccionados para cada componente junto con las fotografías y filmaciones disponibles para las excavaciones realizadas.

\section{Unidad 5 de Cerro Tres Tetas 1}

Se registraron cuatro fogones, localizados principalmente hacia el interior de la cueva, en la zona más oscura (Fig. 1). Se ubican en las cuadrículas C1-E2, D1, G2-G1 y G2-H1 respectivamente. Tres de ellos fueron identificados en la base de la unidad, de donde procede la mayor parte de los elementos recuperados. El restante, ubicado en mayor proporción en la cuadricula $\mathrm{G} 2$, se superpone a otro fogón que ocupa las cuadrículas G2 y H1. Un análisis botánico realizado en una de las muestras de carbón para

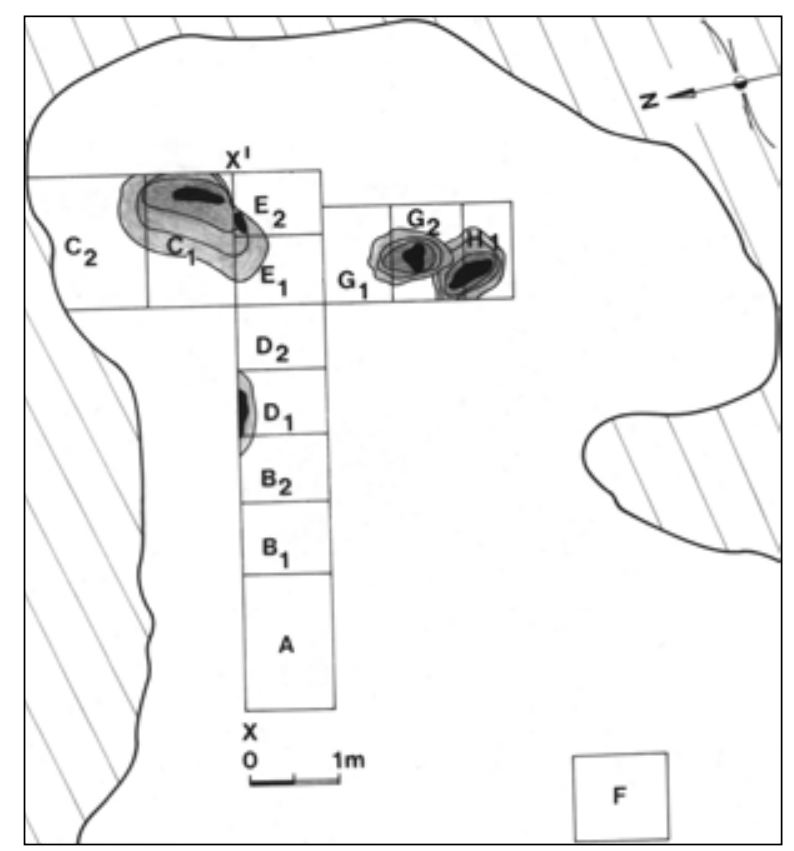

Fig. 1. Distribución en planta de fogones. Unidad 5 de C3T1. Publicado originalmente en Paunero (2000a).

datación radiocarbónica, dio como resultado la pertenencia al género Schinus por lo que probablemente corresponda a Molle (Schinus polygamus) (Paunero y Castro 2001; Steele y Politis 2009).

Todos los fogones son planos y no presentan estructuras limitantes de ningún tipo. En cuanto a sus dimensiones, dos son de aproximadamente 60 x $40 \mathrm{~cm}$, otro es mucho mayor y finalmente del cuarto (ubicado en D1) se desconoce su dimensión total por no estar completamente excavado (Tabla 1). Mientras que dos de los fogones son semicirculares, la estructura más grande es de morfología elíptica irregular.

Considerando su ubicación en planta, vemos que estos se distribuyen de forma mucho más cercana a las paredes de la cueva (su distancia promedio es de $177 \mathrm{~cm}$ tomada desde el centro del fogón y de 140 desde sus bordes) que a la línea de goteo (la distancia promedio es de $726 \mathrm{~cm}$ tomada desde el centro del fogón y de $681 \mathrm{~cm}$ desde sus bordes) (Tabla 1). La distancia promedio entre fogones es de 232 centímetros si se considera el centro de cada estructura, pero de 132 centímetros si lo que se toman son los bordes. Cabe aclarar que este último valor se ve altamente influido por la superposición 
Tabla 1. Dimensiones de los fogones y distancia a la línea de goteo y a la pared de la cueva. Unidad 5 de C3T1. Todos los valores están expresados en $\mathrm{cm}^{*}=$ Parcialmente excavado

\begin{tabular}{|c|c|c|c|c|c|c|}
\hline \multirow[b]{2}{*}{ Ubicación } & \multirow[b]{2}{*}{ Eje mayor } & \multirow[b]{2}{*}{ Eje menor } & \multicolumn{2}{|c|}{ Distancia a línea de goteo } & \multicolumn{2}{|c|}{ Distancia a pared de cueva } \\
\hline & & & $\begin{array}{l}\text { Desde centro } \\
\text { de fogón }\end{array}$ & $\begin{array}{l}\text { Desde límite } \\
\text { de fogón }\end{array}$ & $\begin{array}{l}\text { Desde centro } \\
\text { de fogón }\end{array}$ & $\begin{array}{c}\text { Desde límite } \\
\text { de fogón }\end{array}$ \\
\hline $\mathrm{C} 1-\mathrm{E} 2$ & 120 & 60 & 591 & 543 & 92 & 92 \\
\hline $\mathrm{D} 1^{*}$ & 60 & 8 & 807 & 739 & 160 & 80 \\
\hline $\mathrm{G} 2-\mathrm{G} 1$ & 59 & 40 & 759 & 731 & 252 & 224 \\
\hline $\mathrm{G} 2-\mathrm{H} 1$ & 65 & 40 & 747 & 711 & 204 & 164 \\
\hline
\end{tabular}

parcial de los hogares de G2-G1 y G2-H1. Teniendo en cuenta la superficie total excavada, se registró una proporción de un fogón cada 3,06 m².

\section{Unidad 4 de Casa del Minero 1}

Se identificaron diez fogones que ocupan un área restringida del espacio excavado, en el sector sudeste de la cueva (Fig. 2). Son todos planos y de formas elípticas y semicirculares. No presentan estructuras limitantes de ningún tipo. En cuanto a sus dimensiones, vemos que el eje mayor mide entre 27 y $60 \mathrm{~cm}$, mientras que el eje menor está entre los 20 y los $40 \mathrm{~cm}$ (Tabla 2). Dos fogones han sido parcialmente excavados (B2 y J1-F2) por lo que no contamos con sus dimensiones totales.
Considerando su ubicación en planta, vemos que se concentran en siete de las diecisiete cuadrículas trabajadas (Fig. 2), seis de las cuales presentan al menos dos hogares cada una. Al igual que en la unidad 5 de C3T1, se distribuyen más cerca de las paredes de la cueva (su distancia media es de $106 \mathrm{~cm}$ tomada desde el centro del fogón y de 90 desde sus bordes) que a la línea de goteo (distante en promedio $308 \mathrm{~cm}$ desde el centro del fogón y a 293 desde sus límites) (Tabla 2). Cabe destacar que, en el caso de esta unidad, las distancias obtenidas con respecto a la línea de goteo deben considerarse como valores mínimos, teniendo en cuenta que hemos registrado entre la unidad 4 y la unidad 3 inferior una línea de derrumbes que probablemente afectó en cierta medida la extensión de la cueva. La

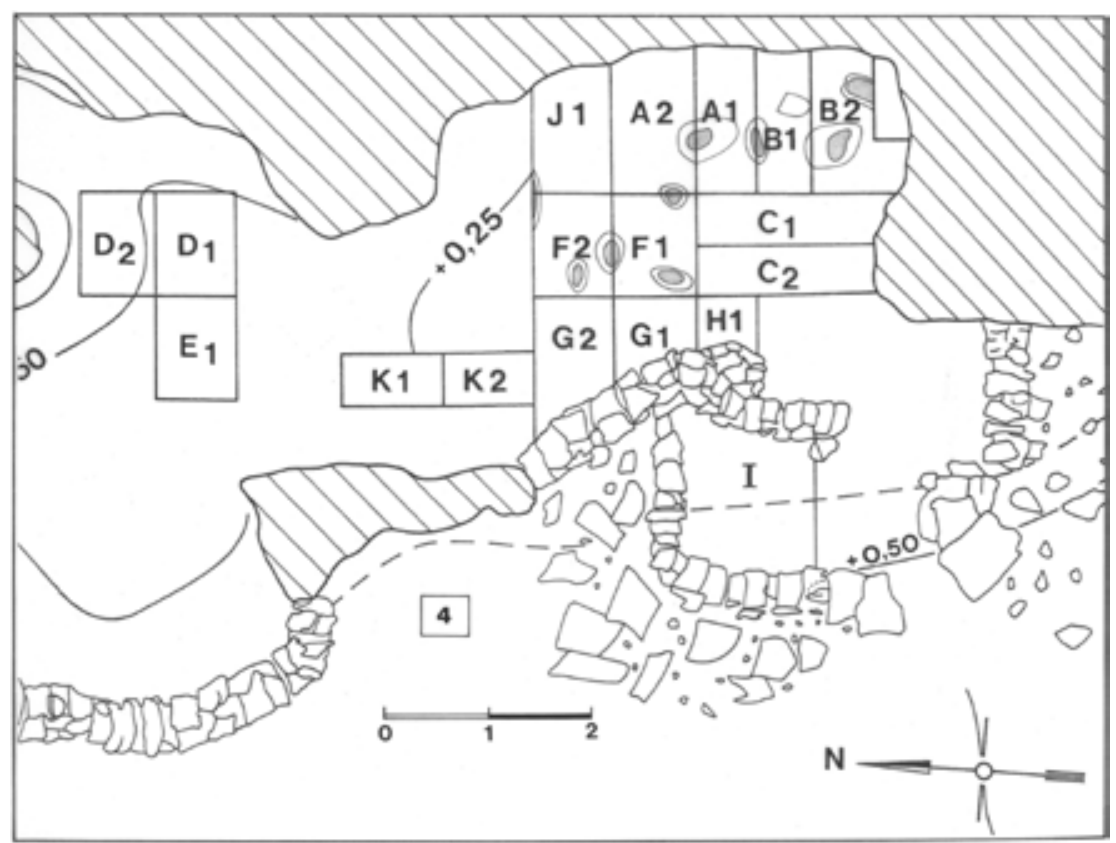

Fig. 2. Distribución en planta de fogones. Unidad 4 de CDM1. Escala en metros. Publicado originalmente en Paunero et al. 2007. 
Tabla 2. Dimensiones de los fogones y distancia a la línea de goteo y a la pared de la cueva. Unidad 4 de CDM1. Todos los valores están expresados en $\mathrm{cm}$. *= Parcialmente excavado.

\begin{tabular}{|c|c|c|c|c|c|c|}
\hline \multirow[b]{2}{*}{ Ubicación } & \multirow[b]{2}{*}{ Eje mayor } & \multirow[b]{2}{*}{ Eje menor } & \multicolumn{2}{|c|}{ Distancia a línea de goteo } & \multicolumn{2}{|c|}{ Distancia a pared de cueva } \\
\hline & & & $\begin{array}{l}\text { Desde centro } \\
\text { de fogón }\end{array}$ & $\begin{array}{l}\text { Desde límite } \\
\text { de fogón }\end{array}$ & $\begin{array}{l}\text { Desde centro } \\
\text { de fogón }\end{array}$ & $\begin{array}{l}\text { Desde límite } \\
\text { de fogón }\end{array}$ \\
\hline A1-B1 & 42 & 22 & 338 & 318 & 85 & 62 \\
\hline B1 & 27 & 20 & 369 & 362 & 49 & 38 \\
\hline B1-B2 & 60 & 40 & 331 & 310 & 74 & 46 \\
\hline B2* & 39 & 26 & 364 & 359 & 33 & 23 \\
\hline A2-A1 & 57 & 35 & 349 & 323 & 87 & 69 \\
\hline F1-A2 & 27 & 20 & 295 & 282 & 136 & 126 \\
\hline $\mathrm{F} 1$ & 40 & 20 & 215 & 205 & 190 & 169 \\
\hline F2-F1 & 38 & 26 & 262 & 244 & 167 & 149 \\
\hline F2 & 31 & 19 & 251 & 236 & 154 & 141 \\
\hline J1-F2* & 55 & 8 & 310 & 295 & 90 & 79 \\
\hline
\end{tabular}

separación promedio entre fogones es de $152 \mathrm{~cm}$ si se considera el centro de cada estructura, pero de $119 \mathrm{~cm}$ si lo que se toman son sus bordes. Teniendo en cuenta la superficie total excavada, se registró una proporción de un fogón cada $1,53 \mathrm{~m}^{2}$.

\section{Unidad 3 Inferior de Casa del Minero 1}

Se identificaron nueve fogones en este componente. Todos son planos, con formas elípticas y subelípticas. No presentan estructuras limitantes de ningún tipo, sin embargo, uno de los fogones fue encendido adyacente a la pared del fondo de la cueva, lo que probablemente le proporcionó cierto reparo y permitió la transferencia de calor por convección. En cuanto a sus dimensiones, los ejes mayores fluctúan entre los 27 y los $67 \mathrm{~cm}$, mientras que los ejes menores están entre los 20 y los $42 \mathrm{~cm}$ (Tabla 3).

Los fogones de esta unidad se encuentran en el área central de la excavación, algo más dispersos que en la unidad 4, ocupando un mayor espacio de la

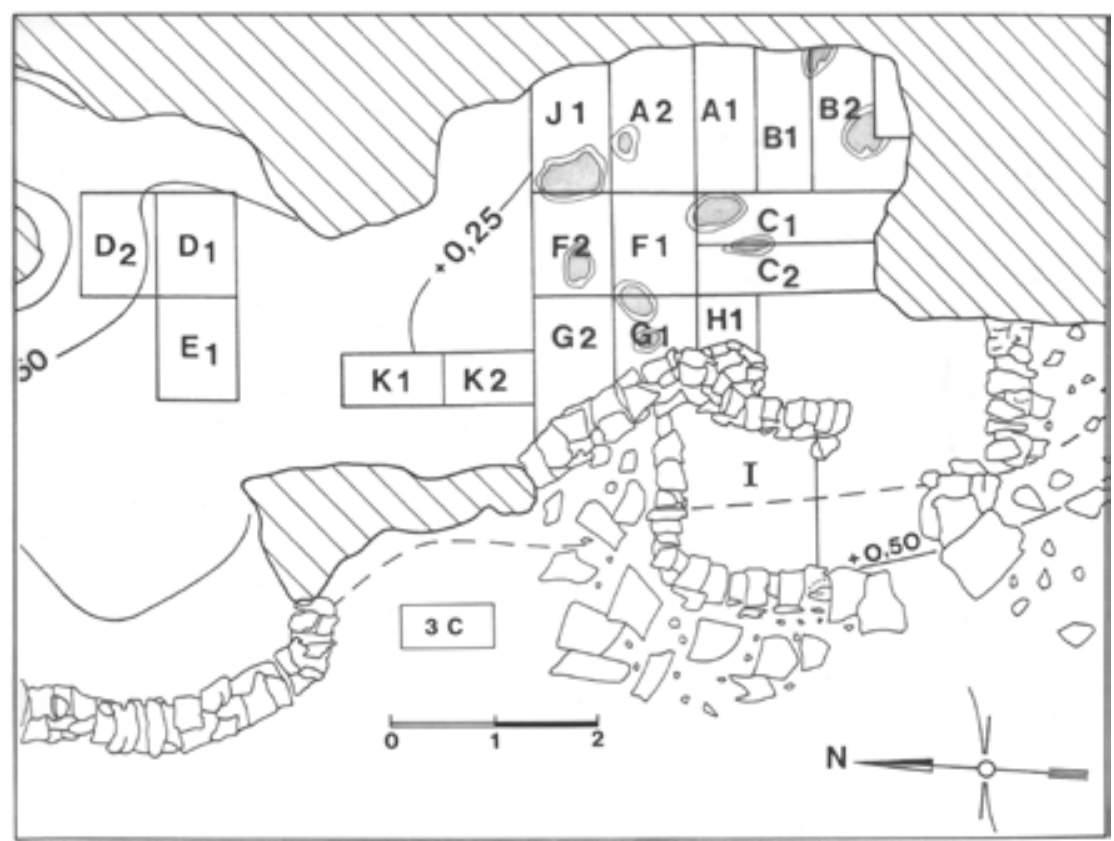

Fig. 3. Distribución en planta de fogones. Unidad 3 inferior de CDM1. Escala en metros. Publicado originalmente en Paunero et al. 2007. 
Tabla 3. Dimensiones de los fogones y distancia a la línea de goteo y a la pared de la cueva. Unidad 3 inferior de CDM1. Todos los valores están expresados en $\mathrm{cm}$.

\begin{tabular}{|c|c|c|c|c|c|c|}
\hline \multirow[b]{2}{*}{ Ubicación } & \multirow[b]{2}{*}{ Eje mayor } & \multirow[b]{2}{*}{ Eje menor } & \multicolumn{2}{|c|}{ Distancia a línea de goteo en $\mathrm{cm}$} & \multicolumn{2}{|c|}{ Distancia a pared de cueva en $\mathrm{cm}$} \\
\hline & & & $\begin{array}{l}\text { Desde centro } \\
\text { de fogón }\end{array}$ & $\begin{array}{l}\text { Desde límite } \\
\text { de fogón }\end{array}$ & $\begin{array}{l}\text { Desde centro } \\
\text { de fogón }\end{array}$ & $\begin{array}{c}\text { Desde límite } \\
\text { de fogón }\end{array}$ \\
\hline A2 & 35 & 25 & 360 & 340 & 78 & 50 \\
\hline B1-B2 & 32 & 25 & 410 & 395 & 0 & 0 \\
\hline B2 & 55 & 42 & 335 & 310 & 40 & 18 \\
\hline $\mathrm{C} 1-\mathrm{C} 2$ & 47 & 20 & 243 & 230 & 103 & 95 \\
\hline $\mathrm{C} 1-\mathrm{F} 1$ & 60 & 35 & 278 & 260 & 158 & 130 \\
\hline F1-G1 & 47 & 30 & 208 & 180 & 193 & 175 \\
\hline G1 & 27 & 22 & 165 & 155 & 170 & 155 \\
\hline F2 & 40 & 30 & 263 & 240 & 150 & 135 \\
\hline F2-J1 & 67 & 42 & 348 & 323 & 90 & 63 \\
\hline
\end{tabular}

cueva, y abarcando diez de las diecisiete cuadrículas trabajadas (Fig. 3), cuatro de las cuales presentan dos fogones cada una. Se distribuyen de forma más cercana a las paredes de la cueva (su distancia media es de $109 \mathrm{~cm}$ tomada desde el centro de la estructura y de $91 \mathrm{~cm}$ desde sus bordes) que a la línea de goteo (alejada en promedio a $290 \mathrm{~cm}$ del centro del fogón y a $270 \mathrm{~cm}$ desde sus límites) (Tabla 3). La distancia promedio entre fogones es de 166 $\mathrm{cm}$ si se considera el centro de cada estructura, pero de $127 \mathrm{~cm}$ si lo que se toman son los bordes. Teniendo en cuenta la superficie total excavada, se registró una proporción de un fogón cada $1,7 \mathrm{~m}^{2}$.

\section{COMPARACIÓN DE LOS FOGONES DE LAS TRES UNIDADES Y DISCUSIÓN DE LOS RESULTADOS}

A continuación realizamos un análisis comparativo del tamaño, distribución y características de los fogones registrados en los tres componentes en estudio. Esto permite observar si existen tendencias generales durante el Pleistoceno final, que posibiliten discutir acerca de diversos aspectos que afectan al manejo del fuego y a las estrategias de uso del espacio intrasitio implementadas durante este período.

Se relevó un total de 23 fogones. Todos son planos; su morfología es mayormente elíptica, aunque en algunos casos son semicirculares. Ninguno de ellos presenta estructuras limitantes de su espacio. Únicamente un fogón de la unidad 3 inferior de CDM1 se presenta adyacente a la pared de la cueva. Esto permitiría la transferencia de calor por convección y además podría ser interpretado como una forma de protección de la estructura.
En este sentido, los fogones de la meseta central que hemos estudiado son acordes a lo que se espera para contextos de ocupaciones poco intensas o de corta duración, donde se destina poca energía en la formatización de los fogones (Nakazawa 2007; Pérez de Micou 1991). Cabe considerar que los fogones planos tienden a alcanzar temperaturas menores que los que tienen forma de cubeta, y a tener menor duración, razón por la cual no resultan morfologías óptimas para ocupaciones prolongadas (Leroi-Gourhan 1979; Marconetto 2005; Nakazawa 2007). Teniendo en cuenta los modelos de poblamiento planteados para este contexto temporal, se ha propuesto que los fogones de este período habrían tenido corta duración y haber sido encendidos para pocos individuos (Stadler 2002; Stadler et al. 2003). De esta manera, los fogones analizados responden a lo esperado para este contexto temporal.

Con respecto a su tamaño, en la Fig. 4 se puede reconocer que los fogones conforman dos grupos en relación con sus dimensiones. Por un lado fogones "chicos" con un diámetro máximo que fluctúa entre los 27 y los $47 \mathrm{~cm}$ y un eje menor, perpendicular al anterior, con dimensiones que están entre los 19 y los $30 \mathrm{~cm}$; estos están presentes sólo en las unidades de CDM1. Por el otro, estructuras "grandes" con un diámetro máximo que va entre 55 y $67 \mathrm{~cm}$ de largo y un eje menor con dimensiones que están entre los 35 y los $42 \mathrm{~cm}$; estas fueron reconocidas en los tres componentes. Por fuera de estos dos grupos sólo quedan cuatro fogones, tres de los cuales no han sido completamente excavados, razón por la cual no se cuenta con sus dimensiones totales. El restante, uno de los hogares de la unidad 5 de C3T1, presenta dimensiones mucho mayores a todos (120 


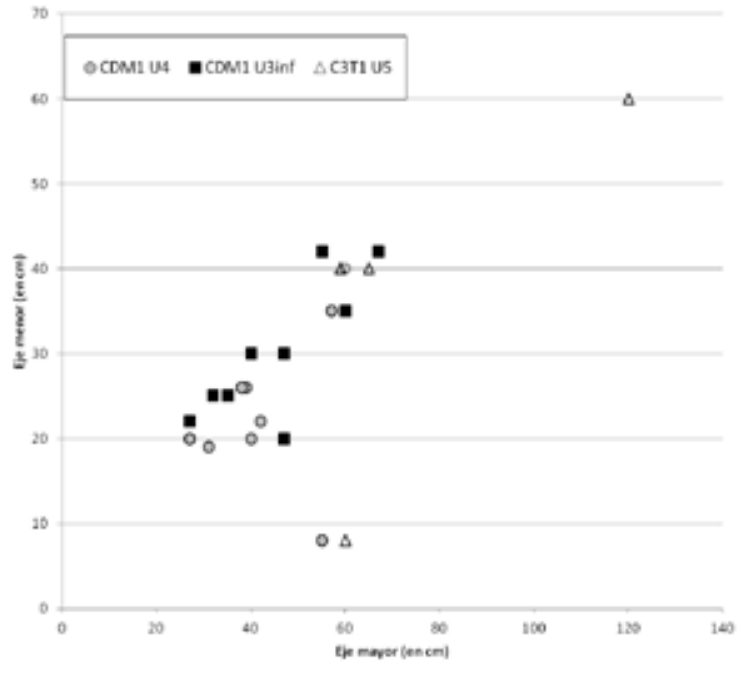

Fig. 4. Dimensiones de los fogones en $\mathrm{cm}$.

$\mathrm{cm}$ por $60 \mathrm{~cm}$ ). Lo mismo se puede observar en el dendograma de la Fig. 5, realizado con aquellos fogones de los que se cuentan las dimensiones totales. En él se observan dos grandes grupos, vinculados a los tamaños arriba mencionados, y por fuera de estos, el fogón de mayores dimensiones de C3T1.

Resulta interesante que los fogones de la unidad 4 de CDM1 tienden a agruparse dentro de los más pequeños, mientras que los de C3T1 se concentran dentro de los más grandes. A este respecto, una posibilidad es que su mayor tamaño relativo en relación con el resto esté indicando que más cantidad de gente haya utilizado las estructuras o que permanecieron durante más tiempo en el sitio (Bartram et al. 1991; Chatters 1987; Pérez de Micou 1991).

Otra posibilidad es que el mayor tamaño de los fogones se deba a funciones específicas a las cuales fuesen destinados estos. Las actividades que implican la utilización del fuego para las que hasta el momento tenemos evidencias en los sitios son el tratamiento térmico de artefactos líticos y la cocción de recursos faunísticos (Frank 2009b, 2011b; Paunero 2009a; Paunero y Castro 2001). Si analizamos el Tabla 4 observamos que no existiría una correlación entre el tamaño de las estructuras de combustión (grandes o chicas de acuerdo a los dos rangos mencionados arriba) y las actividades desarrolladas en los sitios. Por lo tanto, dichas tareas no estarían determinando el tamaño de los fogones. Sabemos que la forma y el tamaño de los fogones no son definitorios por sí mismos de las funciones que cumplieron (Manzi y Spikins 2008) sino que éstos pueden tener diversidad de usos. Nuestras experimentaciones en tratamiento térmico de artefactos líticos utilizando fogones (Cueto y Frank 2008, 2009; Frank 2009a, 2011b) indican que es posible desarrollar este procedimiento de manera exitosa empleando hogares como los presentes en los componentes estudiados. Con respecto a la cocción, las evidencias en la unidad 4 de CDM1 en la que los restos óseos termoalterados, presumiblemente como consecuencia de procesos de cocción (Frank 2011b), rodean tanto estructuras de combustión grandes como chicas, llevan a pensar que probablemente ambos tipos de estructuras hayan sido utilizadas para este fin. Resultan necesarios, sin embargo, otros estudios -por ejemplo análisis antracológicos y micromorfológicos que permitan establecer el tipo de combustible utilizado y las temperaturas alcanzadas- para poder establecer fehacientemente esta afirmación.

De todas maneras, las evidencias disponibles hasta el momento parecen indicar que tanto el tratamiento térmico como la cocción de recursos faunísticos podían ser desarrollados en ambos tipos de estructuras. En consecuencia, postulamos como hipótesis que sus dimensiones podrían variar en función de la intensidad de la ocupación, es decir que podría haber fluctuado la cantidad de personas que ocuparon el sitio en el momento de encendido el fogón, o bien el tiempo que permanecieron en el sitio. Sin embargo, cabe aclarar que existen otros posibles usos del fuego que no dejan un correlato material (como por ejemplo la calefacción) o bien que estos elementos no hayan perdurado en el registro arqueológico (por ejemplo el uso del fuego en el tratamiento térmico de pigmentos o yeso) (Aschero 1983-1985) y que podrían estar afectando el tamaño de las estructuras de combustión. Además, también es posible que otros factores no considerados aquí hayan jugado un papel en el tamaño que adquirieron los fogones.

Tabla 4. Evidencias de tratamiento térmico (TT), cocción y tamaño de fogones por componente (G: Grandes, C: Chicos).

\begin{tabular}{|c|c|c|c|}
\hline Unidad & TT & Cocción & Fogones \\
\hline C3T1 U. 5 & $\mathrm{Si}$ & No & G \\
\hline CDM1 U. 4 & $\mathrm{Si}$ & $\mathrm{Si}$ & G y C \\
\hline CDM1 U. 3 inf. & $\mathrm{Si}$ & $\mathrm{No}$ & G y C \\
\hline
\end{tabular}




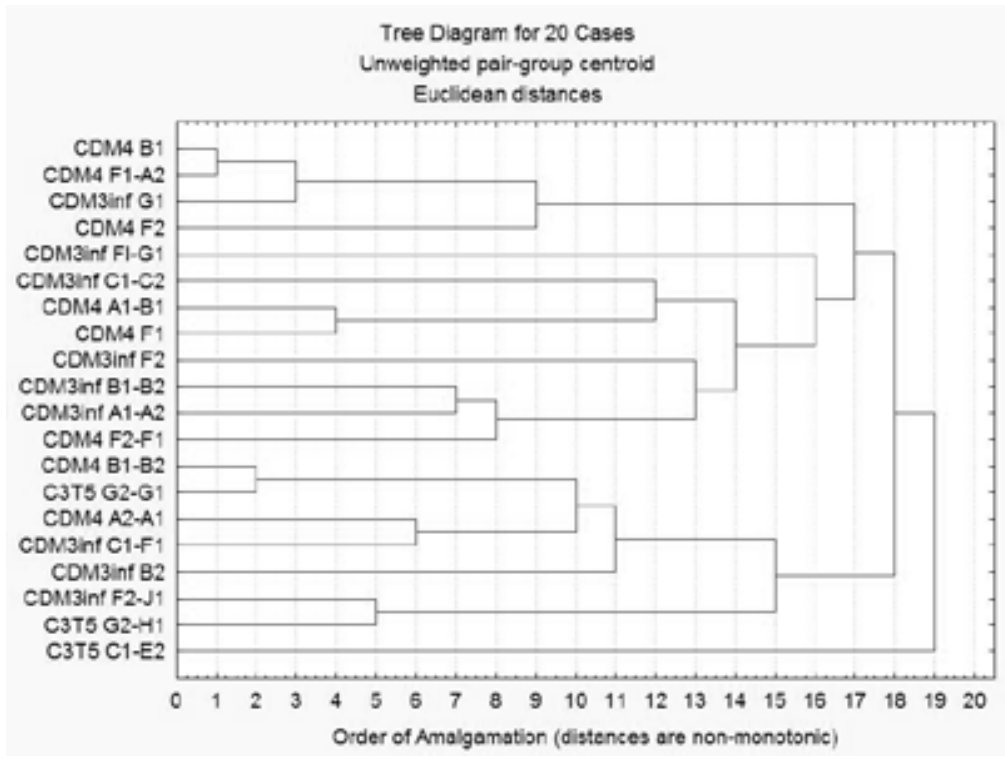

Fig. 5. Dendograma considerando largo y ancho de los fogones. Distancias euclídeas. Método del centroide.

En cuanto a su ubicación, notamos que, como regla general, los fogones se localizan mucho más cerca de las paredes de la cueva que de la línea de goteo (Tabla 5 y Fig. 6). Esto estaría indicando un patrón de selección del espacio para el encendido de las estructuras de combustión, similar al observado en otras partes del mundo (Henry 2003, 2010) y permite generar expectativas útiles a la hora de realizar sondeos iniciales. Esto es, en líneas generales, los fogones habrían sido encendidos en el sector interno de las cuevas, probablemente buscando mayor reparo, fundamentalmente, del viento. Teniendo en cuenta que los fogones funcionan como articuladores del espacio y concentran a su alrededor muchas de las actividades realizadas, es esperable que la zona donde se ubiquen éstos presente también mayor concentración de restos arqueológicos, especialmente en contextos con baja intensidad de ocupación en los cuales se invierte poco trabajo en la limpieza y mantenimiento del espacio ocupado (Bamforth et al. 2005; O'Connell 1987; Schiffer 1972; Stevenson 1991; Vaquero y Pastó 2001). En este sentido, en los tres componentes analizados se ha observado la estructuración de ciertas tareas en torno al fuego. La talla lítica se habría desarrollado, en los tres casos, preferentemente a su alrededor (Frank 2011b; Paunero et al. 2007; Skarbun y Frank 2011). Asimismo, en la unidad 4 de CDM1 también se registraron cerca de estas estructuras actividades de consumo y de procesamiento primario y secundario de fauna (Cueto et al. 2010; Frank 2011b; Paunero et al. 2007) mientras que en C3T1 se identificaron mediante el análisis funcional de artefactos líticos áreas de actividad alrededor del fuego vinculadas principalmente al trabajo en cuero (Paunero y Castro 2001).

Por otra parte, si analizamos la proporción de fogones por área excavada (Tabla 5), observamos que los valores son muchísimo más altos que los relevados por Henry $(2003,2010)$ quien registra un hogar cada $14,7 \mathrm{~m}^{2}$ en contextos arqueológicos y uno cada $23,6 \mathrm{~m}^{2}$ en contextos etnográficos. Esto indicaría que en los componentes analizados las estructuras de combustión tienden a estar agrupadas. Asimismo, si se observa la separación de los fogones dentro de los componentes, existe una similitud notable entre los tres sitios (Tabla 5), especialmente si se considera la distancia entre los bordes de las estructuras (en las tres unidades la distancia promedio está entre los 119 y los $132 \mathrm{~cm}$ ); en tanto si se toman los datos concernientes a los centros de los fogones, la paridad entre las unidades de CDM1 se mantiene, mientras que C3T1 muestra una mayor separación. Henry (2010) observa que la separación promedio entre fogones en componentes en cuevas es de 2,4 m y que este valor se reduce a 
Tabla 5. Promedio por componente de distancias de los fogones a la línea de goteo, las paredes de la cueva y entre sí (valores expresados en $\mathrm{cm}$ ). Relación entre área excavada y cantidad de fogones reconocidos en cada componente.

\begin{tabular}{|c|c|c|c|c|c|c|c|}
\hline \multirow{2}{*}{ Unidad } & \multicolumn{2}{|c|}{ Distancia entre fogones } & \multicolumn{2}{|c|}{ Distancia a línea de goteo } & \multicolumn{2}{|c|}{ Distancia a pared de cueva } & \multirow{2}{*}{$\begin{array}{c}\text { Proporción área } \\
\text { excavada/cant. fogones }\end{array}$} \\
\hline & $\begin{array}{c}\text { Desde centro } \\
\text { de fogón }\end{array}$ & $\begin{array}{l}\text { Desde límite } \\
\text { de fogón }\end{array}$ & $\begin{array}{c}\text { Desde centro } \\
\text { de fogón }\end{array}$ & $\begin{array}{c}\text { Desde límite } \\
\text { de fogón }\end{array}$ & $\begin{array}{c}\text { Desde centro } \\
\text { de fogón }\end{array}$ & $\begin{array}{c}\text { Desde límite } \\
\text { de fogón }\end{array}$ & \\
\hline C3T1 U. 5 & 232 & 132 & 726 & 681 & 177 & 140 & 1 fogón cada 3,06 m² \\
\hline CDM1 U. 4 & 152 & 119 & 308 & 293 & 106 & 90 & 1 fogón cada $1,53 \mathrm{~m}^{2}$ \\
\hline CDM1 U. 3 inf. & 166 & 127 & 290 & 270 & 109 & 91 & 1 fogón cada $1,7 \mathrm{~m}^{2}$ \\
\hline
\end{tabular}

$1,4 \mathrm{~m}$ en aquellos niveles con 11 hogares. En este sentido, en las unidades de CDM1, no sólo los valores se acercan considerablemente a los obtenidos para componentes con abundantes fogones, sino que en ellos además se observa habitualmente más de un fogón en una misma cuadrícula, o bien en cuadrículas adyacentes pero ubicados de manera muy cercana. Todo esto podría estar indicando que éstos no representarían eventos sincrónicos producto de una sola ocupación de la cueva (Paunero et al. 2007). Se ha registrado etnográficamente que existe diversidad en la cantidad de estructuras que son encendidas dentro de una cueva al mismo tiempo, dependiendo, entre otros factores, de la cantidad de gente presente y las funciones destinadas a ellos (Galanidou 2000). Sin embargo, en este caso la cercanía entre ellos no dejaría espacio disponible para ser utilizado, de modo que es esperable que los fogones correspondan a repetidas ocupaciones, más que corresponder a eventos sincrónicos, hecho que también se observa en otros sitios patagónicos tempranos con abundantes estructuras de combustión (Massone 2004).
En este sentido, cabe destacar que de acuerdo a Henry (2003, 2010), aquellos componentes arqueológicos en cuevas que presenten más de 6 fogones estarían indicando más de una ocupación. Considerando esto, los componentes pleistocénicos de CDM1 representarían al menos dos momentos de ocupación.

En contraste, C3T1 podría estar evidenciando una única ocupación. Sin embargo, de acuerdo a su ubicación estratigráfica y horizontal, a las dataciones radiocarbónicas y a la proximidad registrada entre ellos, Paunero (2009a) afirma que estos fogones no representan eventos sincrónicos; esto resulta probable teniendo en cuenta que dos de ellos están parcialmente superpuestos. En consecuencia, es esperable que se trate al menos de dos ocupaciones diferentes. Asimismo, los fechados radiocarbónicos realizados en el sitio (Paunero 1994, 2000a, 2003, 2009a; Paunero y Castro 2001; Steele y Politis 2009), que fueron realizados sobre carbones provenientes de los hogares, brindan información que permite considerar esta situación. Las dataciones realizadas con carbones

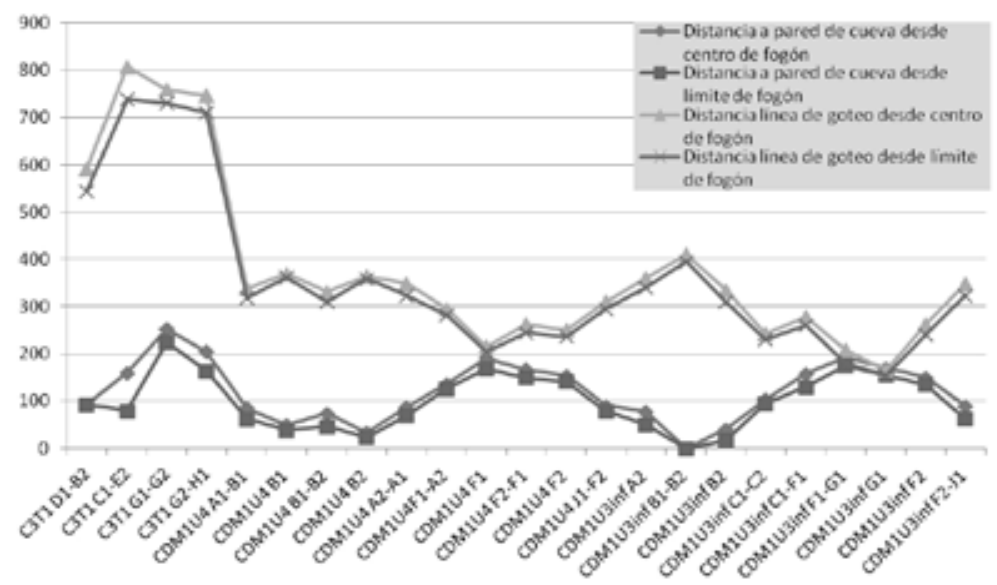

Fig. 6. Comparación de distancia (en $\mathrm{cm}$ ) de los fogones a la línea de goteo y a las paredes de la cueva. 
procedentes del fogón ubicado en las cuadrículas C1-E2 han brindado dos grupos de fechados, uno rondando los 10.900 años ${ }^{14} \mathrm{C} \mathrm{AP}$-con un desvío estandar promedio de 95 años- y el otro los 11.100 años ${ }^{14} \mathrm{C} \mathrm{AP}$-con un desvío estandar promedio de 92 años- . Steele y Politis (2009) plantean como una de las posibilidades con respecto a esta observación que se trate de dos episodios de ocupación con reutilización del fogón. Esto es interesante considerando que estas muestras con fechados divergentes proceden de sectores diferentes de este fogón (Paunero com. pers.), y que esta estructura es la más grande de todas las analizadas, y que por sus dimensiones se diferencia claramente del resto. Algunos autores (Bartram et al. 1991; Chatters 1987) han propuesto que aquellos fogones utilizados más intensamente tienden a ser más grandes que aquellos menos empleados. En este sentido, consideramos factible que el fogón ubicado en C1-E2 haya sido reutilizado -o bien que en realidad corresponda a dos fogones imbricados- seleccionando los ocupantes de la cueva durante diferentes momentos el mismo espacio -o uno inmediatamente adyacente- para encender sus fuegos.

\section{LOS FOGONES DE LA MESETA CENTRAL Y LOS FOGONES FELL 1}

Es escasa la información sistemática concerniente a formas y dimensiones de fogones en la literatura arqueológica de la Patagonia. Una excepción es el caso de las estructuras relevadas y descriptas por Massone y equipo para el área de Magallanes y Tierra del Fuego en Chile -sitios Tres Arroyos, Cueva Fell, Pali Aike, Cueva del Medio y Lago Sofía-, correspondientes a lo que él denomina modalidad Fell 1 (Massone 2002, 2004; Massone y Prieto 2004; Massone et al. 1998) y que son contemporáneos a los que hemos estudiado.

Si realizamos una comparación vemos que estos son planos, mientras que los Fell 1 pueden ser planos, pero también los hay en cubeta, así como grandes manchas carbonosas. Los fogones Fell 1 pueden ser circulares, semicirculares o de forma irregular mientras que en la meseta central de Santa Cruz tienden a ser elípticos o semicirculares. En dos de los hogares de los sitios adscribibles a la modalidad Fell 1, además, se presentan grandes bloques líticos que podrían ser interpretados como límites a las estructuras de combustión (Massone 2002, 2004). En cuanto a sus dimensiones, Massone (2002, 2004) marca que la mayor parte de ellos presenta un diámetro máximo de entre 31 y $55 \mathrm{~cm}$ y sólo un fogón tiene un diámetro mayor a los 55 $\mathrm{cm}$. Este último presenta un diámetro de $107 \mathrm{~cm}$ y sus límites no son definidos (Massone 2002, 2004).

De esta manera, observamos que existen ciertas diferencias entre los fogones de la meseta central y los relevados en Magallanes y Tierra del Fuego. Los Fell 1 presentan una mayor diversidad de morfologías que incluye cubetas e inclusive en algunos casos presentan estructuras limitantes o protectoras. Esto indicaría más trabajo en la formatización de los hogares. En contraste, los de la meseta central muestran un rango mayor de tamaños.

Esto podría revelar que para dos regiones vecinas de la Patagonia meridional, se estarían implementando, a fines del Pleistoceno, estrategias diferentes con respecto al diseño de los fogones. Si bien son necesarios mayor número de estudios, existen diversos factores que podrían influir en la forma en que se diseñaron las estructuras de combustión. Por un lado, es posible que diferencias climáticas estén actuando. En este sentido, los fogones en cubeta permiten alcanzar temperaturas mayores (Leroi-Gourhan 1979; Marconetto 2005), por lo que resultan más óptimos que los planos para ambientes fríos. Por el otro, los fogones en cubeta tienden a perdurar más tiempo, y podrían haber sido preferidos en los casos en que se pretendía ocupar un sitio de forma más prolongada. Finalmente, es factible que las diferencias puedan deberse a usos distintos de las estructuras de combustión, aunque la evidencia contextual indica actividades similares en ambas regiones (Jackson y Prieto 2005; Massone 2004; Massone y Prieto 2004; Paunero 2009b). Esto resalta la importancia de implementar estudios comparativos entre los conjuntos arqueológicos de regiones vecinas, generando enfoques más abarcativos y superadores que nos permitan identificar los factores que inciden en el diseño y funcionalidad de un fogón en un momento dado.

\section{CONCLUSIONES}

Las evidencias analizadas nos han permitido aportar información acerca de diversos aspectos relacionados con el manejo y uso de las estructuras 
de combustión durante el Pleistoceno final en la meseta central de Santa Cruz.

En primer lugar, las características generales de los fogones analizados -planos y sin estructuras limitantes-son acordes con ocupaciones poco intensas, donde se encienden fuegos que requieren poca inversión de energía en su acondicionamiento. Esto es coherente con los modelos de poblamiento y colonización inicial de la Patagonia, para los cuales se plantea una baja densidad demográfica y cortos tiempos de estadía en los sitios.

Asimismo, las evidencias indican que la fluctuación en los tamaños de los fogones podría estar vinculada a cambios en la intensidad de ocupación -ya sea en la cantidad de gente ocupando un sitio o en el tiempo de estadía en el mismo-. Los usos registrados hasta el momento para el fuego en estos componentes no afectarían, por el contrario, las dimensiones de las estructuras de combustión.

Teniendo en cuenta su ubicación dentro de las cuevas, y la distancia inter-fogón, es poco probable que las estructuras de combustión hayan estado activas al mismo tiempo. La abundancia de hogares, muchas veces ubicados de manera cercana entre ellos o inclusive superpuestos podrían estar evidenciando una sucesión de ocupaciones en las cuevas, así como una redundancia en la elección de los espacios utilizados para encender fogones. Es decir, posiblemente los sitios hayan sido ocupados de manera intermitente, por poca gente y/o cortos períodos de tiempo, pero de manera reiterada $y$ seleccionando espacios similares para el encendido de las estructuras de combustión. En este sentido, observamos una tendencia a encender los fogones alejados de la línea de goteo de la cueva y más cercanos a sus paredes.

Finalmente, comparaciones iniciales de los fogones de la meseta central con las estructuras "Fell 1" relevadas para la región de Magallanes y Tierra del Fuego en Chile indican que posiblemente se hayan desarrollado dos estrategias distintas con respecto al diseño de los fogones en estos dos espacios de la Patagonia meridional.

\section{AGRADECIMIENTOS}

Deseo expresar mi agradecimiento a Cecilia Pérez de Micou, Eduardo Moreno y Víctor Durán, jurados de la Tesis Doctoral de la cual surge este trabajo. A Rafael Paunero y Alicia Castro por su dirección y consejos. A Fabiana Skarbun y Manuel Cueto por sus valiosos comentarios. A la Flia. Behm por su cariño y ayuda inestimable durante el trabajo de campo, al igual que a la población y Municipalidad de Puerto San Julián. A dos evaluadores anónimos que con sus comentarios enriquecieron este trabajo. Este trabajo ha sido posible gracias a una beca doctoral del CONICET.

\section{BIBLIOGRAFÍA}

ALPERSON-AFIL, N. 2008. Continual fire-making by Hominins at Gesher Benot Ya'aqov, Israel. Quaternary Science Reviews 27: 1733-1739.

ASCHERO, C. 1983-1985. Pinturas rupestres en asentantamientos cazadores-recolectores: dos casos de análisis aplicando difracción de rayos X. Cuadernos del Instituto Nacional de Antropología XXX: 291-306.

BAMFORTH, D. B, M. BECKER y J. HUDSON. 2005. Intrasite Spatial Analysis, Ethnoarchaeology, and Paleoindian Land-Use on the Great Plains: The Allen Site. American Antiquity 70 (3): 561-580.

BARTRAM, L., E. KROLL y H. BUNN. 1991. Variability in camp structure and bone food refuse patterning at Kua San hunter-gatherer camps. En: The interpretation of archaeological spatial patterning. 77-148. E. Kroll y T. Price. Plenum Press. New York.

BINFORD, L. 1994. En busca del pasado. Descifrando el registro arqueológico. Crítica, Barcelona.

BIRD, J. 1988 Travels and Archaeology in South Chile. University of lowa Press. Iowa City.

BORRERO, L. 1989-90. Evolucion cultural divergente en la Patagonia Austral. Anales del Instituto de la Patagonia (Serie Ciencias Sociales) 19: 133 - 140.

1994-1995. Arqueología de la Patagonia. Palimpsesto. Revista de Arqueología 4: 9-69.

1999. The Prehistoric Exploration and Colonization of Fuego-Patagonia. Journal of World Prehistory 13 (3): 321-355.

CUETO, M. y A. D. FRANK. 2008. Tratamiento térmico de artefactos líticos: estudios experimentales. En: Problemáticas de la arqueología contemporánea. Tomo II: 375-384. Austral y Tamagnini (Coord.). Universidad Nacional de Río Cuarto. Río Cuarto.

2009. Prueba experimental del trabajo del hueso con herramientas líticas. Tratamiento térmico y manifestación de trazas de uso. Patagonia, Argentina. Boletín de Arqueología Experimental Enviado. 
CUETO, M., R.S. PAUNERO y A. CASTRO. 2010. La aplicación del análisis funcional sobre el conjunto artefactual lítico del componente temprano del sitio Casa del Minero 1 para la determinación de operaciones técnicas. En: XVIII Congreso Nacional de Arqueología Chilena. Valparaíso, Chile. En prensa.

CHATTERS, J. 1987. Hunter-Gatherer Adaptations and Assemblage Structure. Journal of Anthropological Archaeology 6: 336-375.

FRANK, A. D. 2009a. El daño térmico en artefactos líticos: estudios experimentales. En: Entre pasados y presentes II. Estudios contemporáneos en Ciencias Antropológicas. 35 - 48. T. Bourlot, D. Bozzuto, C. Crespo, A. Hecht y N. Kuperszmit. Fundación de Historia Natural Félix de Azara. Buenos Aires.

2009b. Tratamiento y Daño Térmico de Artefactos Líticos en los Componentes Tempranos del Sitio Casa Del Minero 1, Santa Cruz, Argentina. Chungará (Arica) En prensa.

2011a. El manejo del fuego en los grupos patagónicos post-hispánicos. Cuadernos del INAPL Enviado.

2011b. Tratamiento térmico y manejo del fuego en sociedades cazadoras-recolectoras de la Meseta Central de Santa Cruz. FCNyM. UNLP. La Plata. Tesis Doctoral MS.

FRANK, A. D. y R.S. PAUNERO. 2009. Análisis de la alteración térmica de los restos óseos procedentes del componente temprano de Cerro Tres Tetas (Meseta Central de Santa Cruz). Evidencia arqueológica y estudios experimentales. En: Arqueología de Patagonia: una mirada desde el último confín 2:750-772. Editorial Utopías. Ushuaia.

FRANK, A. D., F. SKARBUN y M. F. PAUNERO. 2007. Hacia una aproximación de las primeras etapas de reducción lítica en el Cañadón de la Mina, Localidad Arqueológica La María, Meseta Central de Santa Cruz Argentina. Magallania 35 (2): 133-144.

GALANIDOU, N. 2000. Patterns in Caves: Foragers, Horticulturists, and the Use of Space. Journal of Anthropological Archaeology 19: 243-275.

HENRY, D. (Ed.). 2003. Neanderthals in the Levant: Behavioral Organization and the Beginnings of Human Modernity. New approaches to anthropological archaeology. New York, Continuum.

HENRY, D. 2010. The palimpsest problem, hearth pattern analysis, and Middle Paleolithic site structure. Quaternary International: 1-21. En prensa.

JACKSON, D. y A. PRIETO. 2005. Estrategias Tecnológicas y Conjunto Lítico del Contexto Paleoindio de Cueva Lago Sofía 1, Última Esperanza, Magallanes. Magallania 33 (1): 115-120.
LEROI-GOURHAN, A. 1979. Structures de combustion et strucdures d'excavation. Revista do Museu Paulintas XXVI: 9 - 10.

MANZI, L. y P. SPIKINS. 2008. El fuego en las altas latitudes: Los Selk'nam de Tierra del Fuego como referente etnográfico para el Mesolítico europeo. Complutum 19 (1): 79 - 96.

MARCONETTO, M. B. 2005. Recursos forestales y el proceso de diferenciación social en tiempos prehispánicos en el valle de Ambato, Catamarca. FCNyM. UNLP. La Plata. Tesis Doctoral MS

2006. La gente, la leña, el monte. En: El modo de hacer las cosas: 101-128. C. Pérez de Micou (Ed.). FFyL. UBA. Buenos Aires.

MASSONE, M. 2002. El fuego de los cazadores Fell 1 a fines del Pleistoceno. Anales del Instituto de la Patagonia 30: 117 - 131.

2004. Los cazadores después del hielo. Colección de Antropología. Centro de Investigaciones Diego Barros Arana, Dirección de Bibliotecas, Archivos y Museos, Santiago de Chile.

MASSONE, M y A. PRIETO. 2004. Evaluación de la modalidad cultural Fell 1 en Magallanes. Chungará 36 (1): 303-315.

MASSONE, M., A. PRIETO, D. JACKSON, G. CÁRDENAS, M. ARROYO y P. CÁRDENAS. 1998. Los cazadores tempranos y sus fogatas: una nueva historia para la Cueva Tres Arroyos 1, Tierra del Fuego. Boletín de la Sociedad Chilena de Arqueología 26: 11-18.

MIOTTI, L. y M. SALEMME. 2004. Poblamiento, movilidad y territorios entre las sociedades cazadoras-recolectoras de Patagonia. Complutum 15: 177-206.

NAKAZAWA, Y. 2007. Hearth-centered spatial organization: a comparative approach to the study of palimpsests in late upper paleolithic sites in Hokkaido (Japan) and Cantabria (Spain). University of New Mexico. Doctor of Philosophy. Albuquerque, New Mexico. MS.

O'CONNELL, J. 1987. Alyawara Site Structure and Its Archaeological Implications. American Antiquity 52 (1): 74-108.

ODGAARD, U. 2003. Hearth and home of the Palaeo-Eskimos. Études/Inuit/Studies 27 (1-2): 349-374.

PAUNERO, R.S. 1994. El sitio Cueva 1 de la Localidad Arqueológica Cerro Tres Tetas (Estancia San Rafael, provincia de Santa Cruz, Argentina). Anales de Arqueología y Etnología 48/48: 73-90.

2000a. Localidad Arqueológica Cerro Tres Tetas. En: Guía de campo de la visita a Las Localidades Arqueológicas. 89 - 100. L. Miotti, R.S. Paunero, M. Salemme y G. Cattáneo. UNLP. La Plata. 
2000b. Localidad Arqueológica La María. En: Guía de campo de la visita a las Localidades Arqueológicas: La colonización del Sur de América durante la Transición Pleistoceno/Holoceno. L. Miotti; R. Paunero; M. Salemme y R. Cattáneo.

2003. The Cerro Tres Tetas (C3T) locality in the Central Plateau of Santa Cruz, Argentina. Where the South Winds Blow: Ancient Evidence of Paleo South Americans: 33-140. L. Miotti, M. Salemme y N. Flegenheimer (Editor in Chief R. Bonnichsen). Center for the Studies of the First Americans (CSFA) and Texas A \& M University Press.

2009a. Fogones, conjuntos líticos y funcionalidad en el componente pleistocénico del sitio Cueva 1 de Cerro Tres Tetas, provincia de Santa Cruz. En: Arqueología Argentina en los inicios de un nuevo siglo. Tomo 2: 419-428. F. Oliva, N. de Grandis y J. Rodríguez. Universidad Nacional de Rosario. Rosario.

2009b. La colonización humana de la meseta central de Santa Cruz durante el pleistoceno final: indicadores arqueológicos, referentes estratigráficos y nuevas evidencias.En: Arqueología de la Patagonia - Una mirada desde el último confín. Tomo 1: 85 - 100. M. Salemme, F. Santiago, M. Álvarez, E. Piana, M. Vazquez y M. Mansur. Editorial Utopias. Ushuaia.

PAUNERO, R.S. y A. CASTRO. 2001. Análisis lítico y funcionalidad del componente inferior del sitio Cueva 1 , localidad arqueológica Cerro Tres Tetas, provincia de Santa Cruz, Argentina. Anales del Instituto de la Patagonia (Serie Ciencias Sociales) 29: 189-206.

PAUNERO, R.S., M. CUETO, A. D. FRANK, G. GHIDINI, G. ROSALES y F. SKARBUN. 2004. Comunicación sobre campaña arqueológica 2002 en Localidad La María, Santa Cruz. En: Contra Viento y Marea. Arqueología de Patagonia. 797-808. INAPL. Bs.As.

PAUNERO, R.S., A. D. FRANK, F. SKARBUN, G. ROSALES, M. E. CUETO, G. ZAPATA, M. F. PAUNERO, N. LUNAZZI y M. DEL GIORGIO. 2007. Investigaciones Arqueológicas en el Sitio Casa del Minero 1, Estancia La María, Meseta Central de Santa Cruz. En: Arqueología de Fuego Patagonia. Levantando piedras, desenterrando huesos...y develando arcanos. 577-588. Ed: CEQUA. Punta Arenas.

PAUNERO, R.S., M. F. PAUNERO y D. RAMOS. 2008. Artefactos óseos en componentes del Pleistoceno final de las Localidades La María y Cerro Tres Tetas, Santa Cruz, Argentina. Primer Congreso Nacional de Zooarqueología Argentina: Malargüe. MS.
PÉREZ DE MICOU, C. 1991. Fuegos, fogones y señales. Una aproximación etnoarqueológica a las estructuras de combustión en el Chubut medio. Arqueología 1: 125-150.

PIQUÉ, R. 1999. Producción y uso del combustible vegetal: una evaluación arqueológica. CSIC, Madrid.

PODESTÁ, M., R.S. PAUNERO y D. ROLANDI. 2005. El Arte Rupestre de Argentina Indígena: Patagonia. Corpus Antiquitatum Americanensium. Argentina V. Academia Nacional de La Historia. Unión Académique Internationale.

SCHIFFER, M. 1972. Archaeological Context and Systemic Context. American Antiquity 37 (2): 156-165.

SKARBUN, F. 2009. La organización tecnológica en grupos cazadores recolectores desde las ocupaciones del Pleistoceno final al Holoceno tardío, en la Meseta Central de Santa Cruz. FCNyM. UNLP. La Plata. Tesis doctoral MS.

SKARBUN, F. y A. D. FRANK. 2011. Organización espacial intrasitio durante el Pleistoceno final en la Meseta Central de Santa Cruz. Evidencias para el sitio Casa del Minero 1. Relaciones de la SAA En prensa.

SKARBUN, F., A. D. FRANK, M. F. PAUNERO, M. CUETO y G. ROSALES. 2007. Análisis de la tecnología lítica del Sitio Casa del Minero 1, Meseta Central de Santa Cruz. En: Arqueología de Fuego-Patagonia. Levantando piedras, desenterrando huesos... y develando arcanos. 589-600. F. Morello, M. Martinic, A. Prieto y G. Bahamonde (Eds.). Ed: CEQUA. Punta Arenas.

STADLER, N. 2002. El uso del tratamiento térmico sobre las materias primas líticas en el área de Lago Argentino. Facultad de Filosofía y Letras. UBA. Tesis de Licenciatura. Buenos Aires. MS.

STADLER, N., N. FRANCO y L. BORRERO. 2003. El tratamiento térmico y la ocupación de las cabeceras del Río Santa Cruz. En: Análisis, interpretación y gestión en la arqueología de Sudamérica. 19-42. R. Curtoni y M. Endere. INCUAPA - UNICEN. Olavarría.

STEELE, J. y G. POLITIS. 2009. AMS 14C dating of early human occupation of southern South America. Journal of Archaeological Science 36: 419-429.

STEVENSON, M. 1991. Beyond the formation of hearthassociated artifact assemblages. En: The intepretation of archarological spatial patterning. 269-299. E Kroll y D. Price. Plenum Press. New York.

THÉRY-PARISOT, I., L. CHABAL y S. COSTAMAGNO. 2010. Introduction. En: Taphonomie de la combustion des résidus organiques et des structures de combustion en contexte archéologique. 1-4. I. Théry-Parisot, L. Chabal y S. Costamagno. Palethnologie. Revue bilingue de Préhistoire. 
VAQUERO, M. y I. PASTÓ. 2001. The Definition of Spatial Units in Middle Palaeolithic Sites: The Hearth-Related Assemblages. Journal of Archaeological Science 28: 1209-1220.
VAQUERO, M., J. RANDO y M. CHACÓN. 2004. Neanderthal spatial behaviour and social structure: hearth-related assemblages from the Abric Romaní Middle Palaeolithic site. En: Settlement Dynamics of the Middle Palaeolithic and Middle Stone Age II 367-392. N. Conard. Kerns Verlag. Tübingen. 